\title{
Improved pain and quality of life outcomes after percutaneous vertebroplasty for thoraco-lumbar non-osteoprotic compression fractures
}

\author{
Mostafa M. Nabeeh, Hanee A. Awad, Nabil M. Ali
}

Neurosurgery Department, Mansoura University, EGYPT

\begin{abstract}
Introduction: Vertebroplasty is a minimally invasive technique in which percutaneous injection of bone cement under fluoroscopic guidance Percutaneous vertebroplasty (PVP) has been widely and successfully accepted in the treatment of osteoporotic and neoplastic vertebral compression fractures to control pain refractory to medical treatment. However, using of vertebroplasty as primary line treatment for traumatic, non-osteoporotic compression fractures still not widely accepted and considered a debatable issue.
\end{abstract}

Patients and methods: This prospective comparative study was conducted at Neurosurgery department, Mansoura university hospital and Mansoura emergency hospital through the period between January 2015 and March 2016. 20 patients complaining of back pain due to single level thoracolumbar vertebral compression non-osteoprotic fractures were admitted to the study. Patients were divided into two groups 10 patients each, PVP group and conservative group. Outcome were assessed as regard pain improvement using Visual analogue scale VAS and quality of life using short form 36 scale (SF36).

Results: Ten patients in the PVP group received Vertebroplasty, eight males (80\%) and two females (20\%) the age ranged from 29 to 62 years with mean age of $44.2+8.3$ $($ mean+SD) years. The conservative group included ten patients seven males $(70 \%)$ and three females (30\%) the age ranged from 31 to 64 years with mean age of 45.1+9.2 (mean+SD) years. The level of injury ranged from D6 to L4. VAS and SF36 results showed significant improvement in post injection results compared to preinjection and to the conservative group

Conclusion: Percutaneous vertebroplasty is safe and effective procedure to improve pain and quality of life in non osteoprotic patients complaining of traumatic compression fractures of thoraco-lumar region it decreases pain, and provide early ambulation of patients which improve their quality of life without significant morbidity.

\section{INTRODUCTION}

Vertebral compression fractures (VCFs) represent a significant health care problem due to high incidence and their direct and indirect negative impact on quality of life, physical function, mental health and missed work hours as well as the burden on health care system

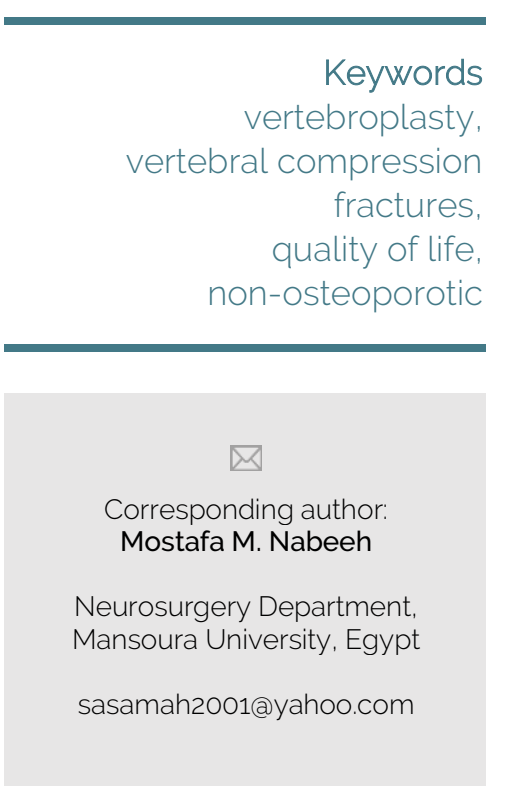

Copyright and usage. This is an Open Access article, distributed under the terms of the Creative Commons Attribution Non-Commercial No Derivatives License (https://creativecommons org/licenses/by-nc-nd/4.0/) which permits noncommercial re-use, distribution, and reproduction in any medium, provided the original work is unaltered and is properly cited.

The written permission of the Romanian Society of Neurosurgery must be obtained for commercial re-use or in order to create a derivative work.

ISSN online 2344-4959

(C) Romanian Society of Neurosurgery

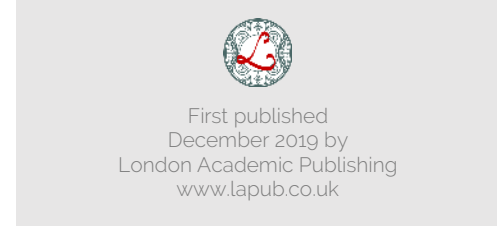


$[114,21,25]$

Vertebroplasty is a minimally invasive technique in which percutaneous injection of bone cement under fluoroscopic guidance into the cancellous bone of a vertebral body with the objective of bone augmentation [19]. Galibert et al. in 1987 were the first to describe and introduced Vertebroplasty, they used the technique for management of vertebral angiomas in seven patients [10]. Percutaneous vertebroplasty is a relatively safe, simple and commonly performed interventional procedure for the management of vertebral compression fractures [11].

Percutaneous vertebroplasty (PVP) has been widely and successfully accepted in the treatment of osteoporotic and neoplastic vertebral compression fractures to control pain refractory to medical treatment [2,12, 15 18, 20,24, 25]. Taylor et al 2007 published a systematic review and found that There is Level III evidence to support balloon kyphoplasty and vertebroplasty as effective therapies in the management of patients with symptomatic osteoporotic vertebral compression fractures refractory to conventional medical therapy.[23]. However, using of vertebroplasty as primary line treatment for traumatic, nonosteoporotic compression fractures still not widely accepted and considered a debatable issue.

Decrease fracture healing, risk of infection and effectiveness of alternative conservative and surgical options are raised as rejection points, while minimally invasiveness than surgery and improvement of pain and quality of life than medical treatment are assumed as advantages of the technique $[5,6,7,8,22]$.

In this study, we compare the percutaneous vertebroplasty PVP and conservative medical treatment in the treatment of traumatic single level non-osteoprotic compression fractures. The 2 groups were compared with respect to baseline pain, quality of life, hospital stay and follow up at 1 and 3 months.

\section{PATIENTS AND METHODS}

This prospective comparative study was conducted at Neurosurgery department, Mansoura university hospital and Mansoura emergency hospital through the period between January 2015 and March 2016. 20 patients complaining of back pain due to single level thoracolumbar vertebral compression fractures were admitted to the study. Patients were divided into two groups 10 patients each, PVP group and conservative group. The choice between the 2 options was based primarily on patient's preferences and, to some extent, on counseling by the neurosurgeon on charge, the first and second authors who did the PVP procedure were called for performing the procedure by the neurosurgeons on duty and didn't involve in the process of decision making.

\section{Pre-operative evaluation}

Patients were assessed clinically by neurological and local examination. This aimed to exclude neurological deficit and identification of painful vertebra by local tenderness at the fracture site and detection of associated medical or surgical comorbidities. It aimed also at defining the degree of pain by Visual analogue scale (VAS) for pain assessment with 0 as no pain and 10 as the worst pain ever experienced. Short form 36 test (SF 36) for quality of life assessment [4].

Imaging studies included Plain X-ray radiography to detect the level, type and number of fractures, degree of collapse (relative vertebral body height) and the degree of kyphosis (vertebral wedge or local kyphotic angle).

The relative vertebral height (RVH) was measured as the sum of the distance along the vertebral borders at the anterior, middle, and posterior locations of the fractured vertebral body in relation to the adjacent intact vertebral body as a reference. The kyphotic angle was determined by using the Cobb method as the angle between the superior and inferior endplates of the collapsed vertebral body. The relative heights of the fractured vertebrae and angle were assessed before and after vertebroplasty on a standard lateral radiograph, and assessed in the conservative group on admission then on discharge and during 1 and 3 months follow up. CT scan with sagittal reconstruction was done for all patients to assess the type of fracture and the integrity of posterior wall of the vertebral body.

Patients included to this study had traumatic fracture with intolerable pain who had a normal BMD t-score (-1 or higher) and their age above 18 years old, compression fracture less than $50 \%$ of vertebral height, intact motor power, no or very small retropulsed segment. While pediatric patients, those having neurological deficit, fracture more than $50 \%$, 
unstable fracture with posterior or middle column disruption and compromise the canal, potential infection, bleeding tendency, oral anticoagulant, had previous spine surgery at same level, those have another painful disease of spine or pathological fractures either osteoporotic or neoplastic were excluded from our study.

\section{Procedure}

Patient was placed in prone position with translucent padding of the regions caudally and cranially from the fractured vertebra(e). oxygen mask was applied Oxygen saturation, blood pressure and heart rate are continuously monitored. sterile drapes were put after adequate sterilization of patient's back. Procedure is performed under local anaesthesia. Identification of the fractured level with the aid of fluoroscopy. (Figure 1).
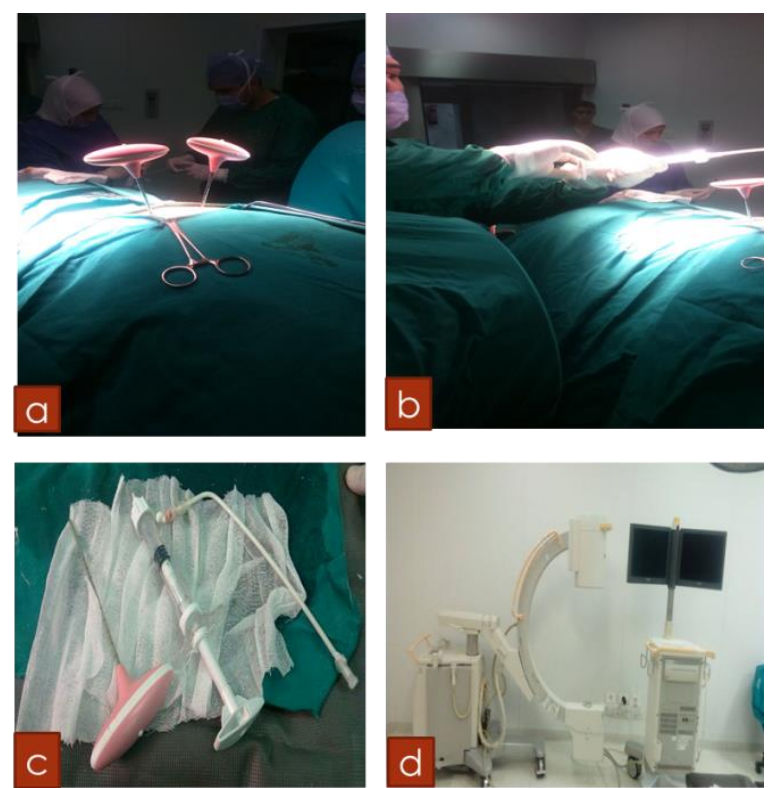

FIGURE 1: Vertebroplasty procedure: a- two injection needles at place b- during injection c- the needle and injector d- C-arm device at neurosurgery department operative room, Mansoura University hospital.

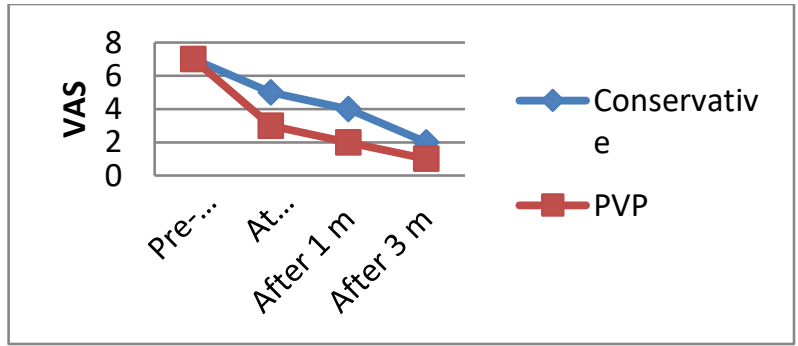

FIGURE 2: Graph of median pain based on VAS score, on admission, on discharge 1 month and 3 months following vertebroplasty. VAS, visual analogue scale.

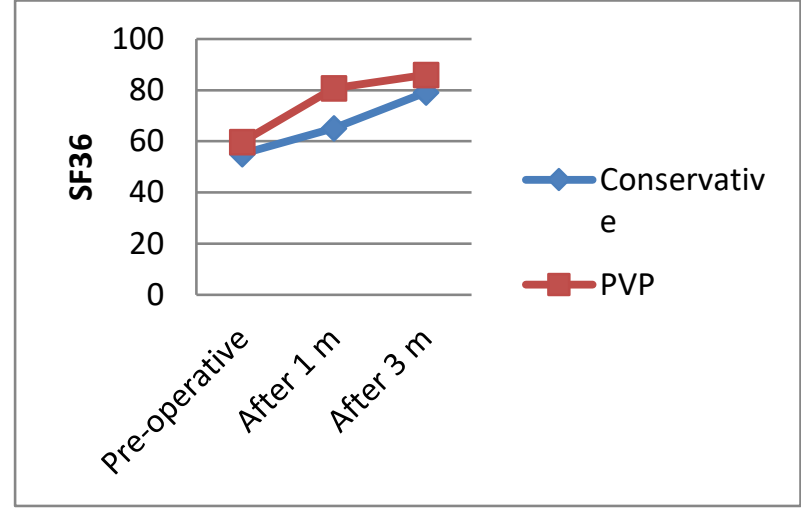

FIGURE 3: Graph of mean quality of life based on SF36 scores on admission, 1 month and 3 months of both groups.
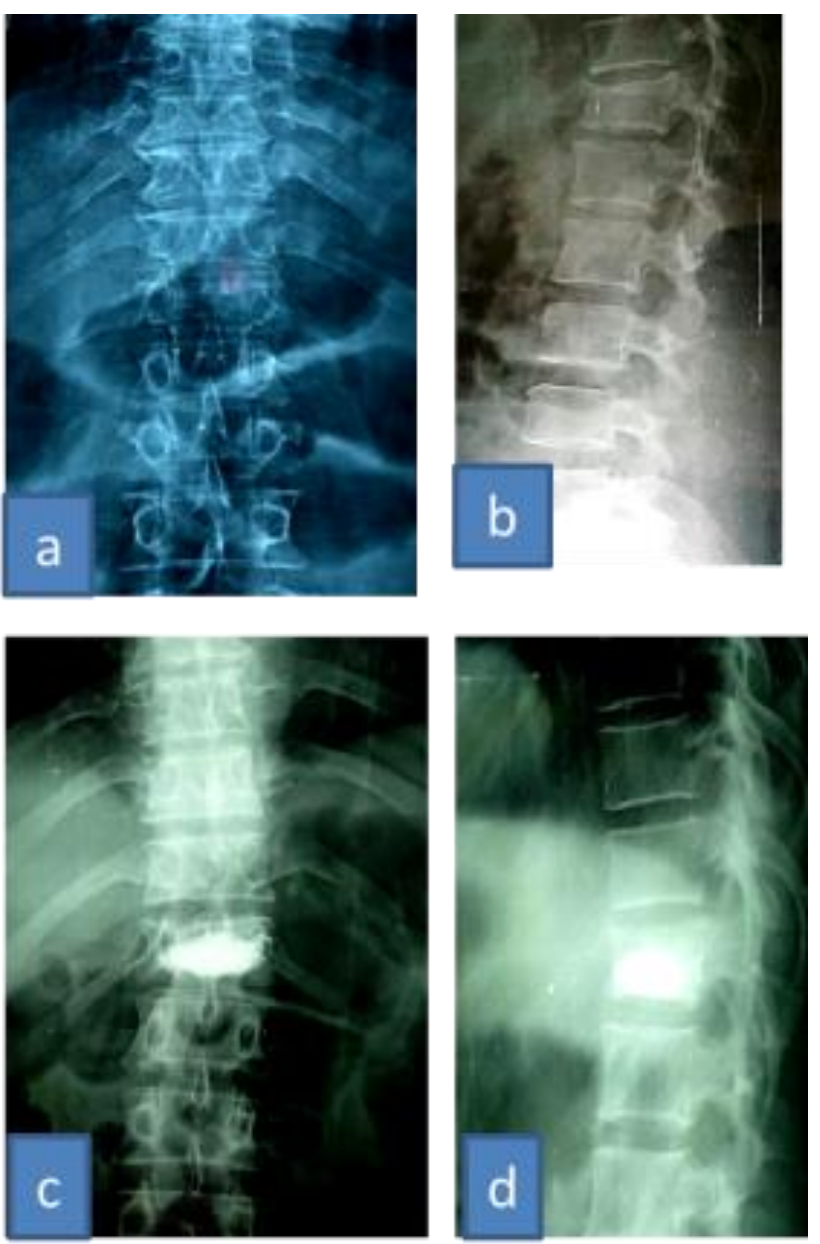

FIGURE 4: Pre- and post-operative x-ray AP \& lat view

The fluoryscopy was manipulated till the fracture level centralized and both pedicle arches were identified on the antero-posterior (AP) image. Local anaesthesia was achieved by injection of Lidocaine $1 \%$ solution using thin spinal needle by which we infiltrated the whole pathway from facet joint till 
subcutaneous tissue. The position of the thin needle used for lidocaine injection determines the direction of the vertebroplasty needle tract during fluoroscopy. Under fluoroscopic guidance one (preferred) or two needles were introduced to pedicle then under guidance of lateral fluoroscopy image the needle was advanced till half of vertebra near midline which confirmed again by AP image.

During insertion of the needle, the bevelled tip was pointed laterally to gain easy access to the pedicle. After pedicle penetration, the bevelled side was rotated medially to avoid breaching of the medial pedicle wall.

The PMMA cement (Exolent spine, ® Italy) was prepared and transferred to an injector. The air was eliminated from the system. After 2-4 minutes of cement mixing (depending on the viscosity of the cement and on the room temperature), the cement reached its proper viscosity (toothpaste-like), and is ready to be injected. The cement was then injected slowly and carefully under constant fluoroscopic imaging in order to achieve good filling of the intertrabecular space of the vertebral body. The injector is disconnected from the needle. the needle(s) was (were) removed with twist to separate the tip from the cement.

\section{Post procedure care:}

A post-procedural CT scan was performed to all cases to assess extent of bone cement and detection of any cement leak. Then the patient was placed in bed for transport to the ward Figure (5).
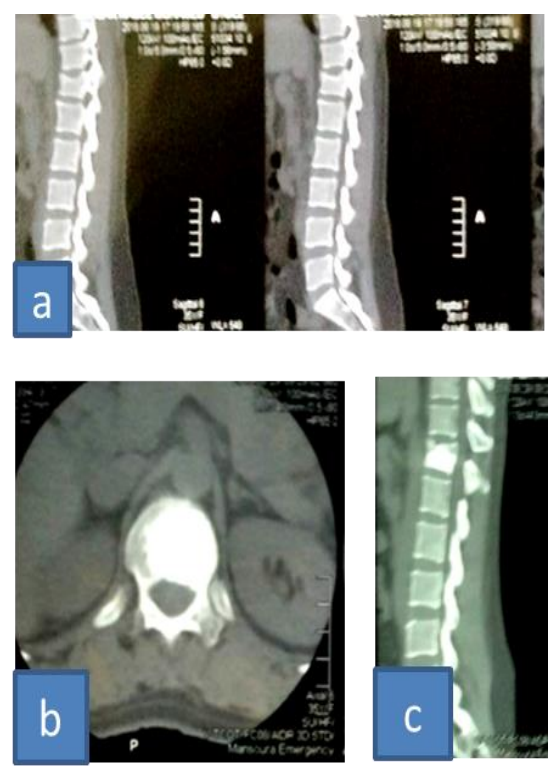
operative sagittal view show

restoration of vertebral height and angles.

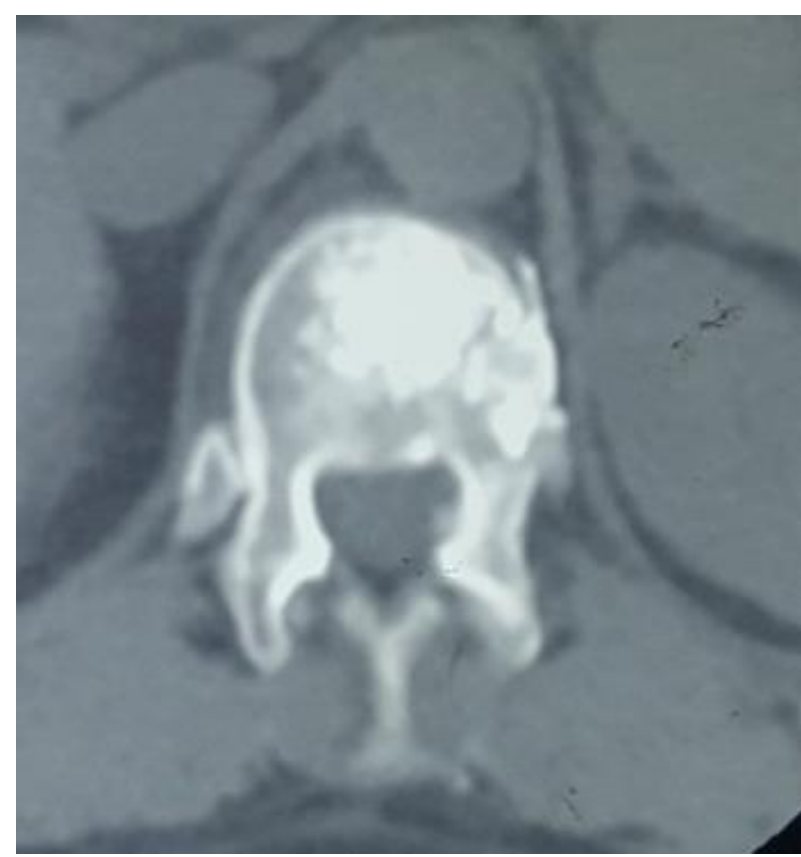

FIGURE 6: Unipedicular injection, cement cross the midline and small part of cement start to leak on the left side of vertebra.

\section{Follow up}

It was carried out at regular intervals; 2 weeks, 1 months and 3 months. In each time the patient were evaluated clinically for Neurological examination, pain by visual analogue scale, evaluation of quality of life by short form 36 test [3]. And radiographically by Plain X-ray.

\section{Statistical analysis:}

Data were analysed using the Statistical Package of Social Science (SPSS) program for Windows (Standard version 21). The normality of data was first tested with one-sample Kolmogorov-Smirnov test. Continuous variables were presented as mean \pm SD (standard deviation) for parametric data and Median for non-parametric data. The two groups were compared with Student t test (parametric data) and Mann-Whitney test (non parametric data).

\section{Level of significance}

For all above mentioned statistical tests done, the threshold of significance is fixed at $5 \%$ level ( $p$-value). The results were considered:
- Non-significant when the probability of error is more than $5 \%(p>0.05)$.

- Significant when the probability of error is less than $5 \%(p \leq 0.05)$. 
The smaller the p-value obtained, the more significant are the result.

\section{RESULTS}

Twenty patients complaining of intractable back pain due to thoracolumbar vertebral compression fractures, and not responding to initial conservative measures and not associated with neurological affection. Ten patients in the PVP group received Vertebroplasty, Eight males (80\%) and two females (20\%) the age ranged from 29 to 62 years with mean age of $44.2 \pm 8.3$ (mean \pm SD) years. six patients injured during fall from height while four sustained road traffic accidents. Unipedicular injection was performed for six vertebrae (60\%), while bipedicular injection performed for four vertebrae (40\%). The level of injected vertebra ranged from D8 to L4. The interval between trauma and injection ranged 3 to 12 days mean was $4.6 \pm 1.8$ the mean post injection hospital stay was 1.7 days ranged from 6 hours to 3 days. The relative kyphotic angle was $10.42 \pm 3$.8. The relative vertebral height was $77 \pm 7 \mathrm{~mm}$

The conservative group included ten patients seven males (70\%) and three females (30\%) the age ranged from 31 to 64 years with mean age of $45.1 \pm 9.2($ mean $\pm S D)$ years. 5 patients injured during fall from height while 5 sustained road traffic accidents. The level of fractured vertebra ranged from D6 to L3. The relative kyphotic angle was 10.17 \pm 3.5 . The relative vertebral height was $78 \pm 2 \mathrm{~mm}$.

TABLE 1: Comparison between both group regarding data on admission.

\begin{tabular}{|l|l|l|l|l|c|}
\hline & \multicolumn{1}{|c|}{$\begin{array}{c}\text { Vertebral } \\
\text { height }\end{array}$} & Kyphotic angle & age & Gender & \multirow{2}{*}{ p-value } \\
\cline { 1 - 5 } & $78 \pm 2.7$ & $10.17 \pm 3.5$ & $45.1 \pm 9.2$ & 73 & \\
\hline Conservative & $78 \pm 2.7$ & $10.42 \pm 3.8$ & $44.2 \pm 8.3$ & 82 & $>0.05$ \\
\hline
\end{tabular}

TABLE 2: Comparison between Conservative and PVP groups regarding VAS preoperative and at different follow up periods.

\begin{tabular}{|l|c|c|c|c|}
\hline \multicolumn{1}{|c|}{ VAS } & Conservative (n=10) & PVP (n=10) & $\begin{array}{c}\text { Mann Whitney } \\
\text { test }\end{array}$ & p- value \\
\hline $\begin{array}{l}\text { Admission } \\
\text { Median (Min-Max) }\end{array}$ & $7(4-9)$ & $7(4-9)$ & 0.194 & 0.846 \\
\hline $\begin{array}{l}\text { VAS at discharge } \\
\text { Median (Min-Max) }\end{array}$ & $5(4-7)$ & $3(1-6)$ & 2.778 & $0.005^{*}$ \\
\hline $\begin{array}{l}\text { VAS after 1m } \\
\text { Median (Min-Max) }\end{array}$ & $4(2-5)$ & $2(0-4)$ & 2.625 & $0.009^{*}$ \\
\hline $\begin{array}{l}\text { VAS after 3m } \\
\text { Median (Min-Max) }\end{array}$ & $2(0-2)$ & $1(0-1)$ & 2.109 & $0.035^{*}$ \\
\hline
\end{tabular}

*significant $p<0.05$

Table 2 showed the results of VAS on admission the differences between both group was statistically insignificant $(P=0.846)$ The pain showed statically significant improvement in PVP group patients from preoperative VAS and compared to conservative group the level of significance was highest on time of discharge $(p=0.005)$ and gradually decreased till 3 months $(p=0.035)$.

In the PVP group Preoperative VAS ranged from 4 to $9(0 \%$ no pain, $0 \%$ mild, $10 \%$ uncomfortable, $40 \%$ distressing, 45\% horrible \& 5\%worst). on discharge VAS ranged between 1 to $6(0 \%$ no pain, $40 \%$ mild, $45 \%$ uncomfortable, $10 \%$ distressing, $5 \%$ horrible \& $0 \%$ worst). Table 1

Comparing unipedicular versus bipedicular techniques results, it is found that no significant difference between improvement of VAS between both techniques Table 3. showed results of VAS in unipedicular and bipedicular techniques. 
TABLE 3: Comparison between unipedicular and bipedicular PVP regarding VAS preoperative and at different follow up periods.

\begin{tabular}{|l|c|c|c|c|}
\hline \multicolumn{1}{|c}{ VAS } & $\begin{array}{c}\text { Unilateral PVP } \\
(\mathrm{n}=6)\end{array}$ & Bilateral PVP (n=4) & $\begin{array}{c}\text { Mann Whitney } \\
\text { test }\end{array}$ & p-value \\
\hline $\begin{array}{l}\text { Pre-injection } \\
\text { Median (Min-Max) }\end{array}$ & $7(5-8)$ & $7(4-9)$ & 0.441 & 0.659 \\
\hline $\begin{array}{l}\text { VAS at discharge } \\
\text { Median (Min-Max) }\end{array}$ & $3(1-3)$ & $4(2-6)$ & 1.453 & 0.146 \\
\hline $\begin{array}{l}\text { VAS after 1m } \\
\text { Median (Min-Max) }\end{array}$ & $2(0-3)$ & $2(1-4)$ & 0.775 & 0.438 \\
\hline $\begin{array}{l}\text { VAS after 3m } \\
\text { Median (Min-Max) }\end{array}$ & $1(0-1)$ & $1(0-1)$ & 0.267 & 0.789 \\
\hline
\end{tabular}

The mean preoperative SF 36 test score was $55.10 \pm 12.57$ pointsin conservative group versus $59.80 \pm 12.16$ in PVP group $(p=0.407)$. While the 1 month after discharge mean SF 36 test score was $65.1 \pm 10.37$ points for conservative group while was $80.70 \pm 4.13(p<0.001)$. on three months follow up SF36 score was $79.10 \pm 6.84$ and $86.00 \pm 6.16$ respectively. The improvement outcome of postoperative values compared with preoperative SF 36 test score was found to be statistically significant $(P<0.001)$. table 4 . As the results of VAS the difference between unipedicular and bipedicular injection in improving quality of on S36 score were insignificant Table 5 Comparing unipedicular versus bipedicular techniques results, the difference was found to be statistically insignificant. Table 5.

There was no mortality in both groups. We had only two cases of cement leakages one case of asymptomatic vascular extravasation of cement and another patient in whom cement leaked into upper disc space.

TABLE 4: Comparison between Conservative and PVP groups regarding SF36 pre injection and at different follow up periods.

\begin{tabular}{|l|c|c|c|c|}
\hline \multicolumn{1}{|c|}{ SF36 } & $\begin{array}{c}\text { Conservative } \\
(\mathbf{n = 1 0 )}\end{array}$ & PVP $(\mathbf{n = 1 0 )}$ & Student t-test & p-value \\
\hline $\begin{array}{l}\text { Pre-injection } \\
\text { Mean } \pm \text { SD }\end{array}$ & $55.10 \pm 12.57$ & $59.80 \pm 12.16$ & 0.850 & 0.407 \\
\hline $\begin{array}{l}\text { SF36 after 1m } \\
\text { Mean } \pm \text { SD }\end{array}$ & $65.1 \pm 10.37$ & $80.70 \pm 4.13$ & 4.29 & $<0.001^{*}$ \\
\hline $\begin{array}{l}\text { SF 36 after 3m } \\
\text { Mean } \pm \text { SD }\end{array}$ & $79.10 \pm 6.84$ & $86.00 \pm 6.16$ & 2.370 & $0.029^{*}$ \\
\hline
\end{tabular}

TABLE 5: Comparison between unilateral and bilateral PVP regarding SF36 preoperative and at different follow up periods.

\begin{tabular}{|l|c|c|c|c|}
\hline \multicolumn{1}{|c}{ SF36 } & $\begin{array}{c}\text { Unilateral PVP } \\
(\mathbf{n = 6 )}\end{array}$ & $\begin{array}{c}\text { Bilateral PVP } \\
(\mathbf{n = 4 )}\end{array}$ & Student t-test & p-value \\
\hline $\begin{array}{l}\text { Pre-injection } \\
\text { Mean } \pm \text { SD }\end{array}$ & $55.67 \pm 11.39$ & $66.00 \pm 11.91$ & 1.381 & 0.205 \\
\hline $\begin{array}{l}\text { SF36 after 1m } \\
\text { Mean } \pm \text { SD }\end{array}$ & $80.00 \pm 4.09$ & $81.75 \pm 4.57$ & 0.633 & 0.544 \\
\hline $\begin{array}{l}\text { SF 36 after 3m } \\
\text { Mean } \pm \text { SD }\end{array}$ & $83.50 \pm 5.36$ & $89.75 \pm 5.91$ & 1.738 & 0.120 \\
\hline
\end{tabular}

Table 5 studies addressed non ostoprotic traumatic fractures 


\begin{tabular}{|l|l|l|l|l|}
\hline Author & Study design & Type of fracture & Number of patients & Year \\
\hline Chen and Lee & Case report & Burst & 1 & 2004 \\
\hline Chen and Lee & Case series & Burst & 6 patients & 2004 \\
\hline Amoretti et al & Case series & Burst & 5 patients & 2005 \\
\hline Huet et al & Case series & Burst & 12 & 2005 \\
\hline Szekely et al & Case report & Burst & 1 & 2009 \\
\hline Knavel et al & Retrospective review & compression & 15 patients & 2009 \\
\hline Szekely Gy & Case series & Compression & 15 patients & 2012 \\
\hline Elnoamany & Case series & compression & 23 patients & 2015 \\
\hline
\end{tabular}

\section{Discussion}

Conservative management, surgical fixation and vertebroplasty are available treatments options for traumatic VCFs. Medical treatment includes rest, thoraco-lumar orthosis and analgesic is indicated in case no neurological deficit, no any signs of instability and kyphotic angle less than 20 degrees and less than $50 \%$ vertebral height loss, which are the same indications for percutenous vertebroplasty. For vertebroplasty there is another relative indication which is the integrity of posterior wall of vertebral body $[14,17]$.

Surgical intervention is not usually the first line of therapy and mostly is necessary if the kyphosis is above 20 degrees to prevent corporeal collapse and prevent subsequent neurological disorders or low back pain. The signs of instability like involvement of the posterior wall, disruption of the spinal arch or interpedicular olisthesis are indication for surgical intervention [1].

Nowadays vertebroplasty become a popular procedure for management of refractory pain in osteoprotic compression fractures and pathological fractures. However, there is a debat about its efficacy in pain relief, quality of life improvement, using it in traumatic cases and its complications. Few reports in litreture were addressed the implication of vertebroplasty in management of the nonosteoprotic traumatic VCFs [3, 6, 7, 9, 14, 21, 22], two of them are case reports and the others are limited sample cohort studies. Table (5) Up to our knowlage, no published comparative study compared the outcome of vertebroplasty to that of conservative management in patients suffering traumatic non osteoprotic thoraco-lumbar VCFs. This study is unique in comparing both treatment modalities in control of pain early mobilization and improving quality of life.

Our results showed that vertebroplasty was effective in reducing pain in all of the vertebroplasty group's patients within a very short period of time. VAS scores obtained on time of patient discharge, 1 month and 3 months after vertebroplasty from our 10 patients of the PVP group showed significant pain relief. And when compared to the VAS scores of the conservative group patients, there were statistically significant superiority to the vertebroplasty group. Pain relief was rapid and marked. This improvement was maintained and continued to improve through the whole follow up period and didn't decline by time.

Our results of pain improvement are supporting the result of Szekely et al in their 15 patients' report; all of them showed more than 5 points improvement of VAS [22]. El noamany reported injection of 29 vertebrae in 23 patients of non-osteoporotic VCFs, all of them showed improved pain scores both on rest and movement, the improvement started 2 hours post injection and continue during follow up, he advocated PVP as first line treatment of VCFs[9]. Chen and Lee performed PVP for management of traumatic Thoracolumbar spine bursting fractures with statistically significant improvement of pain their six patients[6]. Amoretti et al reported 5 patients of stable burst fracture percutaneous vertebroplasty was done under both fluoroscopy and CT guidance, pain improved in 4 out of their 5 patients [3].

The difference between both groups was statistically significant in the time of discharge and one month follow up visit and decline in the 3 months follow up visit. There were no significant differences in these Improvements due to the etiology of the fracture or due to the approach used wither unipedicular or bipedicular or the amount of cement used.

Kallmes et al and Buchbinder et al $[5,16]$ published two randomized trials in 2009, they 
reported that there is no beneficial effect of vertebroplasty compared with a sham procedure ( placebo surgery) in patients with painful osteoporotic vertebral fractures, at 1 week or 1 or 3 months after treatment. No significant differences between groups were seen in the primary outcome of overall pain at 3 months. Despite their population were osteoprotic, we have many concerns about this results, as in our study pain improvement was significant which match with most of studies talking about pain improvement following PVP with a variable degree of pain improvement but in this study noting that there is no difference between PVP and sham procedure is questionable.

Despite small sample size, we found no statistical significance between the six patients received unipedicular injection and the 4 patients received bipedicular injection as regard improving VAS scores and quality of life on SF36. The same conclusion was announced by two studies, Knavel et al. [17] concluded from their retrospective study that, hemivertebroplasty in which cement is instilled in only one half of the vertebral body was as efficacious as bilateral cement infusion [17]. The results of ELnoamany study on non-osteoprotic VCFs confirmed Knavel's study results, since it showed no statistically significant differences in pain or quality of life scores, between hemivertebroplasty and bilateral vertebral filling $[9,17]$ which may be partially explained by increase the hardness of non osteoprotic bone. In our opinion, This piece of information is significant because it support the minimally invasive nature of the procedure which could be performed optimally through on side injection, and it facilitate performing vertebroplasty by local anesthetic infiltration rather than sedative anesthesia and this will encourage patients for taking their decisions and lastly it will decrease cost especially in poor countries.

Pain relief was obviously reflected on the quality of life of the patient and his/her resumption of social activities which were obvious in short form 36 test score improvements. as the short form 36 test SF36 take a survey for last month we found it difficult to be applied on time of discharge and that is why we applied it in one and three months follow up visit. The significant improve in SF36 score results in the vertebroplasty group between pre injection and follow up and between the vertebroplasty group and conservative group support the results accumulated from many previous studies that concluded improvement of quality of life after cement injection for compression fractures either in osteoporotic patients $[4,12,13,18]$ or in traumatic non osteoprotic $\operatorname{VCFs}[3,6,9,14,22]$ but may be our results is the first to compare the conservative treatment to vertebroplasty in head to head prospective randomized study that showed statistical significant improvement in quality of life in the vertebroplasy group.

A comparison of the pre and post vertebroplasty scores in the various SF-36 domains has shown a significant and clinically relevant increase in summary scores, thereby indicating a significant overall increase in the quality of life. During the two weeks after vertebroplasty significant improvement was seen only in the domains of physical function, which is known to have the highest correlation with physical faculties and pain, reflecting the results of the numerical pain score. The role physical and role emotional domains showed an obvious, nonsignificant decrease in the first month, probably due to general post-treatment role-inhibiting behavior. There was a significant improvement in summary scores of SF-36 domains at follow-up at one and three months in our series.

It has great potential to avoid various problems associated with prolonged bed-rest, including high medical expense used for analgesics and other medications, deterioration in bone density and function of the musculoskeletal system and progression of dementia in elderly patients. Persistent back pain may also cause psychological and sleep disorders.

\section{CONCLUSION}

Percutenous vertebroplasty is safe and effective procedure to improve pain and quality of life in non osteoprotic patients complaining of traumatic compression fractures of thoraco-lumar region it decreases pain, and provide early ambulation of patients which improve their quality of life without significant morbidity.

\section{DISCLOSURES}

All The authors have no personal financial or institutional interest in any of the drugs, materials, or devices described in this article

AUTHORS CONTRIBUTIONS

This work was carried out in collaboration between all authors. 
Author Mostafa M. Nabeeh, designed the study, Author Hanee A. Awad wrote the protocol and collect clinical data, Author Nabil M. Ali managed the literature research, Author Mostafa M. Nabeeh performed the statistical analysis and revised the final manuscript. All vertebroplasty procedures were carried out by the first two authors. All authors read and approved the final manuscript.

\section{ABBREVIATIONS}

BMD: Bone Mineral Density.

CT: Computerized Tomography.

PVP: Percutaneous Vertebroplasty

PMMA: Poly Methyl Methacrylate .

RVH: Relative Vertebral Height

SF 36: Short Form 36

VAS: Visual Analog scale

VCF1: Vertebral Compression Fracture.

\section{REFERENCES}

1. Allegretti $L$, Mavilio $N$, Fiaschi $P$, Bragazzi $R$, Pacetti $M$, Castelletti L, Barzaggli R. Intra-operative vertebroplasty combined with posterior cord decompression. A report of twelve cases. Interv Neuroradiol. 2014 Oct31, 20(5):583-90

2. Alvarez L, Alcaraz M, Perez-Higueras A, et al. Percutaneous vertebroplasty: functional improvement in patients with osteoporotic compression fractures. Spine 2006;31:11138.American College of Radiology: John D. Barr, Michelles S. Mathias, Jacques E. Dion. Active Guideline for the Performance of Vertebroplasty. Revised 2009.

3. Amoretti N, Hovorka E, Marcy PY, et al. Burst fracture of the spine involving vertebrae presenting no other lesions: the role of vertebroplasty. Clin Imaging 2005,29:379-82.

4. Brazier J, Roberts J, Deverill M. The estimation of a preference-based measure of health from the SF-36. J Health Econ 2002,21:271-92.

5. Buchbinder R, Osborne RH, Ebeling PR, et al. A randomized trial of vertebroplasty for painful osteoporotic vertebral fractures. New Engl J Med 2009,361:557-68.

6. Chen J-F, Lee S-T. Percutaneous vertebroplasty for treatment of thoracolumbar spine bursting fracture. Surg Neurol 2004,62: 494-500.

7. Chen JF, Wu CT, Lee ST. Percutaneous vertebroplasty for the treatment of burst fractures. Case report. J Neurosurg Spine 2004,1:228-31.

8. Christodoulou A, Ploumis A, Terzidis I, Pournaras I. Vertebral body reconstruction with injectable hydroxyapatite cement for the management of unstable thoracolumbar burst fractures: a preliminary report. Acta Orthop Belg. 2005,71(5):597-603.

9. Elnoamany $\mathrm{H}:$ Percutaneous Vertebroplasty: A First Line Treatment in Traumatic Non-Osteoporotic Vertebral Compression Fractures Asian Spine J 2015,9(2):178-184

10. Galibert $P$, Deramond $H$, Rosat $P$, et al. Preliminary note on the treatment of vertebral angioma by percutaneous acrylic vertebroplasty. Neurochirurgie. 1987,33:166-8.

11. Galibert P, Deramond H, Rosat P, Le Gars D. [Preliminary note on the treatment of vertebral angioma by percutaneous acrylic vertebroplasty, revised]. Neurosurgery. 2006; 33(17):166-8.

12. Garnier L,Tonettia J, Bodina A, Vouaillat $H$, Merloza $P$, Assakerb $\mathrm{R}$ et al: Kyphoplasty versus vertebroplasty in osteoporotic thoracolumbar spine fractures. J. Orthopaedics \& Traumatology: Surgery \& Research. 2012, 98: 112-119.

13. Heini PF, Walchli B, Berlemann U: Percutaneous transpedicular vertebroplasty with PMMA: operative technique and early results: a prospective study for the treatment of osteoporotic compression fractures. Eur Spine J 2000, 9 (5):445-450.

14. Huet H, Cabal P, Gadan R, Borha A,: Emery E. Burstfractures and cementoplasty. J Neuroradiol. 2005,32(1):3341.

15. Kaemmerlen $P$, Thiesse $P$, Jonas $P$, et al.: Percutaneous injection of orthopedic cement in metastatic vertebral lesions. N Engl J Med. 1989;321:121.

16. Kallmes DF, Comstock BA, Heagerty PJ, et al.: A randomized trial of vertebroplasty for osteoporotic spinal fractures. New Engl J Med 2009,361:569-79.

17. Knavel EM, Rad AE, Thielen KR, Kallmes DF.: Clinical outcomes with hemivertebral filling during percutaneous vertebroplasty. AJNR Am J Neuroradiol 2009,30:496-9.

18. Kobayashi K, Shimoyama K, Nakamura K, Murata K: Percutaneous vertebroplasty immediately relieves pain of osteoporotic vertebral compression fractures and prevents prolonged immobilization of patients. J Eur Radiol 2005, 15 : 360-367.

19. McCall T, Cole C, Dailey A.: Vertebroplasty and kyphoplasty: a comparative review of efficacy and adverse events. Curr Rev Musculoskelet Med. 2008,1(1):17-23.

20. Neto PP, Kihara EN, Fontoura EA, Andrioli MS, Junior AA, Romaldiai $\mathrm{H}$ et al: Percutaneous vertebroplasty with polymethylmethacrylate Analysis and results in 57 treated patients. J Einstein 2004, 2(4):278-281

21. Szekely Gy, JÓSVAl A, ERBSZT A, et al: The use of vertebroplasty in traumatic fractures of the thoracolumbal spine. AARMS 2009, Vol. 8, No. (1) 133-139

22. Szekely Gy: The Role of Percutaneous Vertebroplasty in Traumatic Fractures of the Thoracolumbar Spine. Acta Medica Marisiensis 2012,58(6):470-473

23. Taylor RS, Taylor RJ, Fritzell P.: Balloon kyphoplasty and vertebroplasty for vertebral compression fractures: a comparative systematic review of efficacy and safety. Spine 2006,31:2747-55.

24. Tschirhart CE, Finkelstein JA, Whyne CM. Optimization of tumor volume reduction and cement augmentation in percutaneous vertebroplasty for prophylactic treatment of spinal metastases. J Spinal Disord Tech. 2006,19:584-90.

25. Yehya A and El-Nekady A: Percutaneous vertebroplasty for osteoporotic fracture of dorsolumbar and lumbar vertebra: Surgical technique and early outcome. Pan Arab Journal of Neurosurgery 2010, 14:2: 63-68. 